\title{
Mycoplasma detection by triplex real-time PCR in bronchoalveolar lavage fluid from bovine respiratory disease complex cases
}

Jan B. W. J. Cornelissen ${ }^{*}$, Freddy M. de Bree, Fimme J. van der Wal, Engbert A. Kooi, Miriam G. J. Koene, Alex Bossers, Bregtje Smid, Adriaan F. Antonis and Henk J. Wisselink

\begin{abstract}
Background: In this study we evaluated the RespoCheck Mycoplasma triplex real-time PCR for the detection in bronchoalveolar lavage fluid (BALF) of Mycoplasma (M.) dispar, M. bovis and M. bovirhinis, all three associated with bovine respiratory disease (BRD). Primers and probes of the RespoCheck Mycoplasma triplex real-time PCR are based on the V3N4 region of the $16 \mathrm{~S}$ rRNA gene of the three Mycoplasma species.

Results: The analytical sensitivity of the RespoCheck triplex real-time PCR was, as determined by spiking experiments of the Mycoplasma strains in Phosphate Buffered Saline, 300 colony forming units (cfu)/mL for M. dispar, and $30 \mathrm{cfu} / \mathrm{mL}$ for M. bovis or M. bovirhinis. The analytical sensitivity of the RespoCheck Mycoplasma triplex real-time PCRwas, as determined on purified DNA, $10 \mathrm{fg}$ DNA per assay for M. dispar and $100 \mathrm{fg}$ fo rM. bovis and M. bovirhinis. The analytical specificity of the RespoCheck Mycoplasma triplex real-time PCR was, as determined by testing Mycoplasmas strains $(n=17)$ and other bacterial strains $(n=107), 100,98.2$ and $99.1 \%$ for M. bovis, M. dispar and M. bovirhinis respectively. The RespoCheck Mycoplasma triplex real-time PCR was compared with the PCR/DGGE analysis for M. bovis, M. dispar and $M$. bovirhinis respectively by testing 44 BALF samples from calves.
\end{abstract}

Conclusion: In conclusion, the RespoCheck PCR assay can be a valuable tool for timely and accurate detection of three Mycoplasma species associated with in bovine respiratory disease.

Keywords: Bovine Mycoplasma, M. dispar, M. bovis, M. bovirhinis, Triplex PCR, RespoCheck, Bovine respiratory disease

\section{Background}

Bovine respiratory disease complex (BRDC) is a global problem causing severe economic losses to the cattle farming industry through mortality, loss of production, and treatment costs $[1,2]$. It has a complex etiology that involves various pathogens, host factors, and environmental factors. Viruses such as bovine herpes 1 virus (BoHV-1, parainfluenza virus 3 (PBIV-3), bovine respiratory syncytial Virus (BRSV), respiratory bovine coronavirus $(\mathrm{BoCoV})$ and bovine viral diarrhoea virus (BVDV) in conjunction with stress factors have been implicated as causes of respiratory tract infections of cattle by immunosuppression and damage to the respiratory epithelium [3]. A primary viral infection can be followed by

\footnotetext{
* Correspondence: jan.cornelissen@wur.nl

Department of Infection Biology, Central Veterinary Institute of Wageningen UR, P.O. Box 658200, AB, Lelystad, The Netherlands
}

an opportunistic secondary infection with bacteria like Mannheimia haemolytica, Pasteurella multocida, Histophilus somni, or Trueperella pyogenes [2, 4, 5], but these bacteria could also act as primary pathogen. In addition it has become increasingly clear that Mycoplasmas are important contributors to BRD, either as primary pathogens or in co-infection [2, 6-9]. M. bovis is the best known Mycoplasma species causing respiratory disease [4, 7], but also $M$. dispar and $M$. bovirhinis have been associated with BRD [2,9-11]. M. bovis has not only been identified as a primary or opportunistic pathogen in BRD in beef cattle worldwide, but it has also been implicated in other clinical manifestations in cattle, such as mastitis, otitis, arthritis, and reproductive disorders [7]. $M$. bovirhinis and $M$. dispar are regularly isolated from the nasal cavity of cattle with respiratory disease and are 
usually regarded as an opportunistic pathogen in respiratory diseases [7, 12].

Bacteriological, serological and histopathological examinations are important tools to detect particular animal-carriers of Mycoplasma [13], however, these assays are time-consuming, insensitive and can give false positive results. Bronchoalveolar lavage fluid (BALF) from calves with BRD may contain various potential pathogens, but additional antibiotic use in the affected herds can inhibit cultivation and thereby can cause falsenegative test results. In BRD, differential diagnosis of these pathogens with rapid turnaround time procedure is essential to implement appropriate treatment and intervention measures in a timely manner. Rapid detection of these pathogens at the early stage of outbreak can contribute substantially to minimize the spread of infection and increase treatment efficiency. Today quick, highly sensitive and species-specific PCRs are used in the diagnosis of Mycoplasma-associated diseases for $M$. dispar [14, 15], M. bovis [4, 16] and M. bovirhinis [17] in BALF or nasal swabs. Combining a 16S Ribosomal DNA PCR with denaturing gradient gel electrophoresis fingerprinting (PCR/DGGE) enabled the simultaneous detection of mixed Mycoplasma populations, however information about the detection limit in clinical samples is limited [18]. Additionally, a DNA microarray assay was developed for the parallel detection of $37 \mathrm{Myco-}$ plasma species [19], in which species-specific probes derived from the $23 \mathrm{~S}$ rRNA and tuf genes were used for species differentiation.

Multiplex real-time PCR could be a promising and practical approach to speed up the differential diagnosis from 1 to 2 weeks for traditional culture to $24 \mathrm{~h}$, with limited expenses. This will make diagnostic testing more accessible for veterinary practitioners and thereby improve BRD diagnosis. This report describes the RespoCheck triplex PCR developed by Central Veterinary Institute (CVI, Lelystad, The Netherlands) for detection of three Mycoplasma species.

\section{Methods}

\section{Strains and growth conditions}

M. bovis (ATCC 25025) and M. bovirhinis (ATCC 5189985) were purchased from the ATCC (United Kingdom (U.K.), Guernsey, Ireland, Jersey and Liechtenstein) and cultured in Heart Infusion Broth Medium (Difco, Detroit, Mich.). All isolates were grown at $37{ }^{\circ} \mathrm{C}$ and $5 \% \mathrm{CO}_{2}$ for seven days in a modified standard mycoplasma broth medium [20] containing $19 \mathrm{~g}$ of Heart Infusion Broth, $50 \mathrm{~mL}$ of liquid yeast extract (10\% [vol/vol]; Oxoid, London, United Kingdom), $2 \times 10^{6} \mathrm{U}$ of penicillin G (Hoechst, Frankfurt, Germany), and $200 \mathrm{~mL}$ of heatinactivated $\left(56{ }^{\circ} \mathrm{C}, 30 \mathrm{~min}\right)$ horse serum per liter. Stocks of each isolate were prepared by freezing $1 \mathrm{~mL}$ portions of a
$10 \mathrm{~mL}$ logarithmic-phase broth culture with $15 \%$ glycerol at $-80{ }^{\circ} \mathrm{C}$. Cultures were titrated on Heart Infusion Agar and were shown to contain $7 \times 10^{6} \mathrm{cfu} / \mathrm{mL}$ for $M$. bovis and $4 \times 10^{5} \mathrm{cfu} / \mathrm{mL}$ for $M$. bovirhinis. $M$. dispar NCTC 10125) was provided by Helena Windsor (Mycoplasma Experience LTD, Bletchingley, UK) with a titre of $1.6 \times 10^{7} \mathrm{cfu} / \mathrm{mL}$. In addition, DNA from 14 Mycoplasma strains (Table 1) were provided by Prof. Konrad Sachse (Friedrich-LoefflerInstitut, Federal Research Institute for Animal Health, Bundesforschungsinstitut für Tiergesundheit, Jena, Germany).

Hundred and seven bacterial isolates, representing 39 different species, were used to evaluate of specificity of the RespoCheck Mycoplasma triplex real-time PCR assay (Table 2). These included isolates associated with BRD and isolates associated with other bovine diseases. Prior to testing by PCR, the identity of the isolates was confirmed using MALDI-TOF mass spectrometry (MS Bruker MALDI Biotyper Microflex, version 3.1 with the reference database version 3.1.66 Bruker Daltonics $\mathrm{GmbH}$, Germany).

\section{Field samples and isolation of DNA}

Calves $(n=44)$ with or without BRD (increased respiratory rate and/or dyspnoea) were sampled for diagnostic purposes. Sampling of the calves was granted an exemption from requiring ethics approval by the institutional Animal Experiment Commission "Dier Experimenten Commissie (DEC) Lelystad (2013111.b)" because sampling was performed for diagnostic purposes. BAL samples were obtained as described [21]. Approximately 35-75 ml BAL was obtained from each calf after instillation of $100 \mathrm{ml}$ PBS with 10\% Fetal Calf serum (FCS). Foam, large purulent exudates and blood clots were removed from the BALF samples under aseptic conditions. BALF $(25 \mathrm{~mL})$ was centrifuged $\left(4600 \times \mathrm{g}, 10 \mathrm{~min}, 4{ }^{\circ} \mathrm{C}\right)$. Sediment was resuspended in $0.5 \mathrm{~mL}$ Dulbecco's minimal essential medium (DMEM) with 5\% FCS, carefully added to $1 \mathrm{~mL}$ freeze medium (DMEM, 50\% FCS and $20 \%$ DMSO) and frozen at $-80{ }^{\circ} \mathrm{C}$. The BALF supernatants were also stored at $-80{ }^{\circ} \mathrm{C}$.

For testing the influence of centrifugation of BALF samples $\left(4600 \times \mathrm{g}, 10 \mathrm{~min}, 4{ }^{\circ} \mathrm{C}\right)$ on the PCR results we tested three variants of BALF samples: without centrifugation, supernatant and pellet obtained after centrifugation (50 times concentrated). DNA was extracted from $200 \mu \mathrm{L}$ aliquots of BALF samples. We used the MagNA Pure LC Total Nucleic Acid Isolation Kit (Roche Applied Science), with the Total NA External_lysis" protocol (Version 2.11). With the MagNA Pure LC Total Nucleic Acid Isolation Kit) 32 samples can processed per run. In all runs a positive control (a mix of $1.4 \times 10^{6} \mathrm{cfu} / \mathrm{mL}$ M. bovis, $0.5 \times 10^{7} \mathrm{cfu} / \mathrm{mL} M$ dispar 
Table 1 Mycoplasma strains ( $n=17)$, which were used as reference material

\begin{tabular}{|c|c|c|c|c|}
\hline \multirow[t]{2}{*}{ Species (Type strain) } & \multirow[t]{2}{*}{ ID } & \multicolumn{3}{|l|}{ Ct-values } \\
\hline & & M. bovis & M. dispar & M. bovirhinis \\
\hline M. agalactiae (PG2) & $\mathrm{R} 41^{\mathrm{b}}$ & 20.9 & - & - \\
\hline M. alkalescens $P G$ 31/D 12 & $\mathrm{R} 18^{\mathrm{b}}$ & - & $35.7^{\mathrm{a}}$ & - \\
\hline M. bovis PG45 & $\mathrm{R} 9^{\mathrm{b}}$ & 19.4 & - & - \\
\hline M. bovirhinis $P G 43$ & $\mathrm{R} 12^{\mathrm{b}}$ & - & - & 25.8 \\
\hline M. bovigenitalium PG11 & $\mathrm{R} 8^{\mathrm{b}}$ & - & - & - \\
\hline M. californicum ST-6 & $R 26^{b}$ & - & - & - \\
\hline M. canadense $275 \mathrm{C}$ & $\mathrm{R} 22^{\mathrm{b}}$ & - & - & - \\
\hline M. canis, PG14 & $R 74^{b}$ & - & - & $20.0^{\mathrm{a}}$ \\
\hline M. dispar 462/2. & $\mathrm{R} 11^{\mathrm{b}}$ & - & 18.7 & - \\
\hline $\begin{array}{l}\text { M. leachii PG50 } \\
\text { (former M. bovine group VII) }\end{array}$ & $\mathrm{R} 23^{\mathrm{b}}$ & - & - & - \\
\hline $\begin{array}{l}\text { M. mycoides subsp. Mycoides PG1 } \\
\text { (former Small Colony Type) }\end{array}$ & $\mathrm{R} 84^{\mathrm{b}}$ & - & - & - \\
\hline Acholeplasma axanthum $\mathrm{S743}$ & $\mathrm{R} 17^{\mathrm{b}}$ & - & $33.1^{\mathrm{a}}$ & - \\
\hline A. laidlawii PG8 & $\mathrm{R} 10^{\mathrm{b}}$ & - & - & - \\
\hline A. oculi 19-L & $\mathrm{R} 62^{\mathrm{b}}$ & - & - & - \\
\hline M. bovis & ATCC 25025 & 23.9 & - & - \\
\hline M. dispar (NCTC 10125) & ATCC 27140 & - & 20.3 & - \\
\hline M. bovirhinis & ATCC 5189985 & - & - & 20.9 \\
\hline
\end{tabular}

${ }^{a}$ Cross-reactions in the RespoCheck triplex Mycoplasma PCR

${ }^{\mathrm{b}}$ ID Friedrich-Loeffler-Institut

and $1.3 \times 10^{5} \mathrm{cfu} / \mathrm{mL}$ M. bovirhinis) and a negative water control (NTC) was included.

\section{RespoCheck primers and probes}

To enable testing of testing for BRD associated pathogens in a routine setting, real-time PCRs for detection of viral, bacterial and mycoplasma pathogens in bronchoalveolar lavage fluid (BALF) of calves have been set up by the Central Veterinary Institute (Lelystad, The Netherlands) under the name RespoCheck. Primers and probes specific for the bacterial 16S, V3 and V4 regions were based on the Full length, bacterial $16 \mathrm{~S}$ sequences (50,000 in July 2012) were used from the nuccore database at the National Center for Biotechnology Information (NCBI, USA, http://www.ncbi.nlm.nih.gov/nuccore). For $M$. bovirhinis and $M$. dispar the nearly full length $16 \mathrm{~S}$ sequences were used. These sequences and their taxonomic information were used to build an Insigniabased database [22] from which pathogen-specific sequence regions were extracted with special interest for the V3 and V4 region because these sequences are often targeted for metagenomic next-generation sequencing (NGS) [23]. Using the identified regions, primers and probes were designed with AlleleID 7.8. (Premier Biosoft, palo Alto, USA). The resulting triplex PCR was designated RespoCheck Mycoplasma triplex real-time PCR The specificity of the Mycoplasma primers and probes was also verified against V3-V4 partial sequences of $M$. flocculare, M. ovipneumonia and M. hyopneumonia.

\section{RespoCheck triplex and single real-time PCR}

The QuantiFast triplex Kit Real Time-PCR kit (Qiagen) was used for the RespoCheck Mycoplasma triplex realtime PCR. The assays were conducted in a $20 \mu \mathrm{l}$ reaction mix containing $5 \mu$ of the nucleic acid sample, $250 \mathrm{nM}$ of each primer, $100 \mathrm{nM}$ of each MGB probe, $1 \times$ QuantiFast triplex Real Time-PCR Master Mix and sterile deionised water. All reactions were conducted with an ABI-7500 with the following cycling parameters: $95^{\circ} \mathrm{C}$ for $15 \mathrm{~min}$, followed by 40 cycles of $94{ }^{\circ} \mathrm{C}$ for $15 \mathrm{~s}$ and $60{ }^{\circ} \mathrm{C}$ for $60 \mathrm{~s}$. The machine was set to acquire fluorescence on the FAM, VIC, and NED channels for respectively $M$. bovis, $M$. dispar and M. bovirhinis All primers and probes were obtained from Life Technologies Europe BV (Bleiswijk, the Netherlands). The final results were analysed using ABI-7500 software (Version 1.4). Samples with a $\mathrm{Ct}$ of 40 cycles or less were considered to be positive.

\section{Evaluation of the analytical sensitivity and the analytical specificity}

The analytical sensitivity of the RespoCheck triplex PCR was defined as the ability to detect the lowest concentration of $M$. bovis, $M$. dispar and M. bovirhinis expressed as a concentration (cfu/mL) [24]. The analytical 
Table 2 Bacterial strains ( $n=107)$, that were used as reference material

\begin{tabular}{|c|c|c|}
\hline Identification (number of isolates tested) & CCUG identification $^{c}$ & Source \\
\hline Acidovorax spp. (3) & $N A^{c}$ & CVI collection ${ }^{a}$ \\
\hline Actinomyces & NA & CVI collection ${ }^{a}$ \\
\hline Aerococcus viridans & NA & CVI collection ${ }^{b}$ \\
\hline Bibersteinia trehalosi & Pasteurella trehalosi & CCUG 37711 \\
\hline Biberstenia trehalosi 20 AA III 3 E3 & NA & CVI collection ${ }^{a}$ \\
\hline Biberstenia trehalosi 21 AA III 3 E4 & NA & CVI collection ${ }^{\mathrm{a}}$ \\
\hline Brucella abortus & NA & CVI collection ${ }^{b}$ \\
\hline Comamonas kerstersii & NA & CVI collection ${ }^{a}$ \\
\hline Corynebacterium bovis (2) & NA & CVI collection ${ }^{b}$ \\
\hline Corynebacterium pseudotuberculosis & NA & CVI collection ${ }^{b}$ \\
\hline Escherichia coli & NA & CVI collection ${ }^{b}$ \\
\hline Gallibacterium anatis (5) & NA & CVI collection ${ }^{a}$ \\
\hline Hafnia alvei & NA & CVI collection ${ }^{a}$ \\
\hline Histophilus somni & NA & ATCC $22132^{e}$ \\
\hline Histophilus somni (4) & NA & CVI collection ${ }^{a}$ \\
\hline Klebsiella oxytoca & NA & CVI collection ${ }^{b}$ \\
\hline Klebsiella pneumoniae & NA & CVI collection ${ }^{b}$ \\
\hline Lactobacillus mucosae & NA & CVI collection ${ }^{a}$ \\
\hline Lactococcus garvieae & NA & CVI collection ${ }^{b}$ \\
\hline Lactococcus lactis & NA & CVI collection ${ }^{b}$ \\
\hline Listeria monocytogenes & NA & CVI collection ${ }^{b}$ \\
\hline Mannheimia heamolytica & NA & ATCC 14003 \\
\hline Mannheimia heamolytica & NA & CVI collection ${ }^{a}$ \\
\hline Mannheimia haemolytica & Mannheimia glucosida & CCUG 38457-T \\
\hline Mannheimia granulomatis & Mannheimia granulomatis & CCUG 45422-T \\
\hline Mannheimia granulomatis 25 AA III 3 E8 & NA & CVI collection ${ }^{a}$ \\
\hline Mannheimia haemolytica & Mannheimia ruminalis & CCUG 38470-T \\
\hline Mannheimia haemolytica (5) & NA & CVI collection ${ }^{a}$ \\
\hline Mannheimia haemolytica 3 AA III 2 H2 & NA & CVI collection ${ }^{a}$ \\
\hline Mannheimia varigena & Mannheimia varigena & CCUG 38462-T \\
\hline Mannheimia varigena 19 AA III 3 E2 & NA & CVI collection ${ }^{a}$ \\
\hline Mannheimia varigena 24 AA III 3 E7 & NA & $\mathrm{CVI}$ collection ${ }^{\mathrm{a}}$ \\
\hline Micrococcus luteus & NA & CVI collection ${ }^{b}$ \\
\hline Moraxella bovis & NA & CVI collection ${ }^{b}$ \\
\hline Moraxelle lacunata (2) & NA & CVI collection ${ }^{a}$ \\
\hline Mycobacterium avium subsp. paratuberculosis & NA & CVI collection ${ }^{b}$ \\
\hline Mycobacterium bovis & NA & CVI collection ${ }^{b}$ \\
\hline Mycobacterium tuberculosis & NA & CVI collection ${ }^{\mathrm{b}}$ \\
\hline Neisseria zoodegmatis & NA & CVI collection ${ }^{a}$ \\
\hline Pantoea agglomerans Erwina herbicola $(n=13)$ & NA & CVI collection ${ }^{a}$ \\
\hline Pasteurella multocida & NA & ATCC $15743^{e}$ \\
\hline Pasteurella multocida & NA & CVI collection ${ }^{a}$ \\
\hline Pasteurella multocida & Bisgaard Taxon 13 & CCUG $16497^{d}$ \\
\hline
\end{tabular}


Table 2 Bacterial strains ( $n=107)$, that were used as reference material (Continued)

\begin{tabular}{|c|c|c|}
\hline Pasteurella multocida & Bisgaard Taxon 13 & CCUG $16498^{\mathrm{d}}$ \\
\hline Pasteurella multocida & Pasteurella multocida ss gallicida & CCUG $17978-T^{d}$ \\
\hline Pasteurella multocida & Pasteurella multocida ss septica & CCUG $17977-\mathrm{T}^{\mathrm{d}}$ \\
\hline Not typable & Pasteurella aerogenes & CCUG $27905^{d}$ \\
\hline Proteus mirabillis & NA & CVI collection ${ }^{a}$ \\
\hline Pseudomonas aeruginosa & NA & CVI collection ${ }^{b}$ \\
\hline Psychrobacter spp. & NA & CVI collection ${ }^{\mathrm{a}}$ \\
\hline Salmonella enteritica ssp. enteritica serovar Dublin & NA & CVI collection ${ }^{b}$ \\
\hline Salmonella enteritica ssp. enteritica serovar Typhinurium & NA & CVI collection ${ }^{b}$ \\
\hline Serratia marcescans & NA & CVI collection ${ }^{b}$ \\
\hline Staphylococcus aureus & NA & CVI collection ${ }^{b}$ \\
\hline Staphylococcus epidermidis & NA & CVI collection ${ }^{b}$ \\
\hline Streptococcus agalactiae & NA & CVI collection ${ }^{b}$ \\
\hline Streptococcus bovis (5) & NA & CVI collection ${ }^{\mathrm{a}}$ \\
\hline Streptococcus dysgalactiae & NA & CVI collection ${ }^{b}$ \\
\hline Streptococcus faecalis & NA & CVI collection ${ }^{b}$ \\
\hline Streptococcus hyointestinalis & NA & CVI collection ${ }^{a}$ \\
\hline Streptococcus pluranimalium (5) & NA & CVI collection ${ }^{a}$ \\
\hline Streptococcus pneumoniae & NA & CVI collection ${ }^{b}$ \\
\hline Streptococcus spp. (3) & NA & CVI collection ${ }^{\mathrm{a}}$ \\
\hline Streptococcus uberis & NA & CVI collection ${ }^{b}$ \\
\hline Trueperella pyogenes & NA & ATCC $9731^{e}$ \\
\hline Trueperella pyogenes (5) & NA & CVI collection ${ }^{a}$ \\
\hline Yersinia enterolytica & NA & CVI collection ${ }^{b}$ \\
\hline Yersinia pseudotuberculosis & Pasteurella lymphangitidis & CCUG $27188-T^{d}$ \\
\hline
\end{tabular}

asolated from lungs of calves

${ }^{\mathrm{b}}$ Isolated from other tissues of cattle as lungs

'Not applicable

${ }^{d}$ CCUG: Culture Collection University of Götenborg, Sweden

eATCC: American Type Culture Collection, USA

All bacterial strains, except the CCUG strains, were from an in-house strain collection

sensitivity of the single and triplex PCRs for M. bovis, $M$. dispar and $M$. bovirhinis was determined with DNA isolated from $200 \mu \mathrm{L}$ culture (M. bovis, M. dispar and $M$. bovirhinis strain) in a volume of $200 \mu \mathrm{L}$ elution buffer at a final DNA concentration of $10 \mathrm{ng} / \mu \mathrm{L}$. This DNA preparation was tested in seven 10-fold serial dilutions ( $5 \mu \mathrm{L}$ per assay) in PBS, resulting in a range with $10 \mathrm{ng}$ down to $1 \mathrm{fg}$ Mycoplasma DNA per assay. The $\mathrm{Ct}$ was determined for each sample by single and RespoCheck triplex real-time PCR with a threshold of $50 \%$ of the Delta Rn value (log). The threshold was manually set at 0.04 in the linear phase of the amplification plot, whereby the Slope and Correlation Coefficient values were 3.22 and $99.99 \%$ respectively.

The analytical sensitivity of the M. bovis, $M$. dispar and $M$. bovirhinis single and RespoCheck triplex real-time PCR, was also determined by testing a mixture of $M$. bovis $\left(3 \times 10^{6} \mathrm{cfu} / \mathrm{mL}\right), M$. dispar $\left(3 \times 10^{6} \mathrm{cfu} / \mathrm{mL}\right)$ and $M$. bovirhinis $\left(3 \times 10^{5} \mathrm{cfu} / \mathrm{mL}\right)$ in seven 10 -fold serial dilutions in BALF of specific pathogen free (SPF) calves of 3-4 weeks old. Dilution resulted in a series of $M$. bovis, $M$. dispar and $M$. bovirhinis spiked BALF samples, ranging from $3 \times 10^{6} \mathrm{cfu} / \mathrm{mL}$ down to $0.3 \mathrm{cfu} / \mathrm{mL}$. Total DNA was isolated from each $200 \mu \mathrm{l}$ sample with the MAGNA pure isolation kit and the $\mathrm{Ct}$ was determined for each sample $(5 \mu \mathrm{l})$ by both the single and RespoCheck triplex PCR assays. The slope of the curve, the efficiency and the detection limit (for DNA ng/ $\mu \mathrm{l}$; for cells $\mathrm{cfu} / \mathrm{mL}$ ) for each PCR was determined. To determine the analytical specificity of the designed RespoCheck triplex PCR, 17 Mycoplasma isolates and 107 bacterial strains (Table 2) were tested.

\section{Diagnostic sensitivity and specificity in BALF samples from calves.}

For determining the diagnostic specificity, BALF samples were analysed with the PCR/DGGE method by the 
Animal and Plant Health Agency (APHA, Mycoplasma Team, Addlestone Surrey, UK) as earlier described [18, 25]. To determine the analytical sensitivity of the PCR/ DGGE analysis, four 10 -fold serial dilutions of $M$. bovis $\left(7 \times 10^{4} \mathrm{cfu} / \mathrm{mL}\right), M$. dispar $\left(16 \times 10^{4} \mathrm{cfu} / \mathrm{mL}\right)$, and $M$. bovirhinis $\left(0.5 \times 10^{4} \mathrm{cfu} / \mathrm{mL}\right)$, were prepared in PBS. Samples were sent to the APHA and analysed using the PCR/DGGE method.

\section{Sequencing amplicons}

16S rDNA PCR-sequencing was used for confirmation of the results of RespoCheck Mycoplasma triplex realtime PCR. 16S rDNA of the DGGE positive /PCR positive $(n=5)$ and DGGE negative /PCR positive $(n=5)$ was amplified using the specific Mycoplasma primers of the RespoCheck Mycoplasma triplex realtime PCR. DNA was sequenced by BaseClear (Leiden, the Netherlands) by an automated DNA sequencer. The nucleotide sequences were compared with GenBank sequences using the Basic Local-Alignment Search Tool(BLAST) of the NCBI-NIH for homology [26]. Pairwise sequence alignments were performed using the Clustal algorithm implemented in the program DNA star (DNASTAR Inc., Madison, WI).

\section{Analyses of sensitivity and specificity}

The analytical sensitivity of the RespoCheck triplex PCR was determined by its ability to detect a low concentration of M. bovis, M. dispar and M. bovirhinis and therefore expressed as a concentration (ng/assay and $\mathrm{cfu} / \mathrm{mL}$ )
[24]. The analytical specificity of the assay was calculated for each target microorganism using the following definition for specificity as the percentage of true negative samples/ the number of true negative samples and the number of false positive samples [27].

Calculation of diagnostic sensitivity, specificity and Cohen's Kappa Coefficient was performed as described [28]. We therefore used the results of the PCR/DGGE analysis as reference standard.

\section{Statistical analyses}

Differences in PCR results were analysed for statistical significance by the non-parametric Mann-Whitney U test in the GraphPad Prism version 5.0 software, with $P<0.05$ considered significant.

\section{Results}

Analytical sensitivity and linear detection range of the RespoCheck triplex

The linearity of quantification of the RespoCheck triplex Mycoplasma real-time PCR was established through a linear regression plot by plotting the Ct-values against the values of $\log 10$ DNA concentration tested per reaction. The $M$. dispar single and RespoCheck triplex realtime PCR showed a linear detection range from $10 \mathrm{ng}$ to 10 fg DNA per assay with a linear correlation $\left(R^{2}\right)$ value of 0.999 (Table 3; Fig. 1.). The M. bovis and M. bovirhinis single and RespoCheck real-time PCR showed a linear detection range from from $1 \mathrm{ng}$ to $100 \mathrm{fg}$ DNA per assay, with a $\mathrm{R}^{2}$ value of 0.999 (Table 3; Fig. 1). In BALF

Table 3 Performance of the RespoCheck Mycoplasma real-time PCR in which the M. dispar, M. bovis and M. bovirhinis DNAs were diluted in PBS (A) or cells were spiked in BALF (B)

\begin{tabular}{|c|c|c|c|c|c|c|}
\hline \multicolumn{7}{|l|}{$\bar{A}$} \\
\hline \multirow[t]{2}{*}{ PCR } & \multirow[t]{2}{*}{ Agent } & \multicolumn{5}{|c|}{ Real time PCR } \\
\hline & & $R^{2}$ & Slope & Efficiency (\%) & Linearity (ng) & Detection limit (ng/assay) \\
\hline \multirow[t]{3}{*}{ Singleplex PCR } & M. dispar & 0.9995 & -3.3836 & 97.49 & $10 \mathrm{ng}-10 \mathrm{fg}$ & $10 \mathrm{fg}$ \\
\hline & M. bovis & 0.9966 & -3.1137 & 109.49 & $10 \mathrm{ng}-10 \mathrm{fg}$ & $10 \mathrm{fg}$ \\
\hline & M. bovirhinis & 0.9955 & -3.5033 & 92.95 & $10 \mathrm{ng}-10 \mathrm{fg}$ & $10 \mathrm{fg}$ \\
\hline \multirow[t]{3}{*}{ Triplex PCR } & M. dispar & 0.9989 & -3.1175 & 109.3 & $10 \mathrm{ng}-10 \mathrm{fg}$ & $10 \mathrm{fg}$ \\
\hline & M. bovis & 0.9955 & -3.6240 & 88.8 & $10 \mathrm{ng}-100 \mathrm{fg}$ & $100 \mathrm{fg}$ \\
\hline & M. bovirhinis & 0.9939 & -3.3735 & 97.9 & $10 \mathrm{ng}-100 \mathrm{fg}$ & $100 \mathrm{fg}$ \\
\hline \multicolumn{7}{|l|}{ B } \\
\hline \multirow[t]{2}{*}{ PCR } & Agent & \multicolumn{5}{|c|}{ Real time PCR } \\
\hline & & $R^{2}$ & Slope & Efficiency (\%) & Linearity (CFU/ml; $\log 10)$ & Detection limit (CFU/assay) \\
\hline \multirow[t]{3}{*}{ Singleplex PCR } & M. dispar & 0.995 & $3.248 \pm 0.1276$ & 103.2 & $6.5-2.5$ & $1-2$ \\
\hline & M. bovis & 0.995 & $3.453 \pm 0.1178$ & 94.8 & $6.5-1.5$ & 0.5 \\
\hline & M. bovirhinis & 0.981 & $3.395 \pm 0.2698$ & 97.0 & $5.5-1.5$ & 0.5 \\
\hline \multirow[t]{3}{*}{ Triplex PCR } & M. dispar & 1.000 & $3.534 \pm 0.04608$ & 91.9 & $6.5-2.5$ & $1-2$ \\
\hline & M. bovis & 0.993 & $3.462 \pm 0.1440$ & 94.5 & $6.5-1.5$ & 0.5 \\
\hline & M. bovirhinis & 0.965 & $2.750 \pm 0.3014$ & 131.0 & $5.5-1.5$ & 0.5 \\
\hline
\end{tabular}




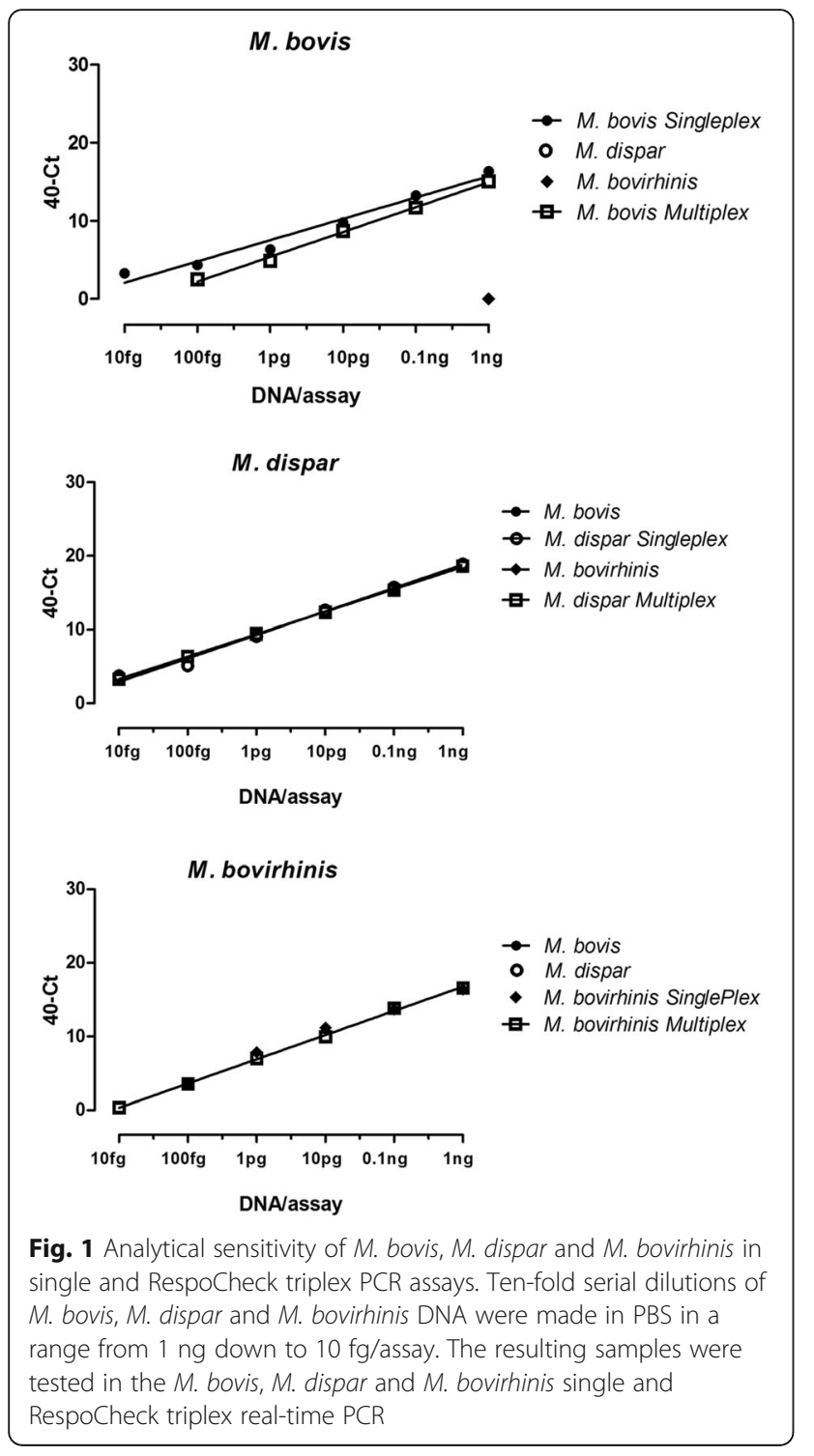

spiked samples, the detection limit of the RespoCheck triplex real-time PCR was $300 \mathrm{cfu} / \mathrm{mL}$ for $M$. dispar, and $30 \mathrm{cfu} / \mathrm{mL}$ for M. bovis or M. bovirhinis (Table 3; Fig. 2). In the RespoCheck Mycoplasma real-time PCR, $5 \mu \mathrm{L}$ was tested and the analytical sensitivity was therefore 1-15 cfu/assay. A good linear correlation $\left(R^{2}>0.96\right)$ was found between the values of BALF spiked samples and the Ct-values in the RespoCheck Mycoplasma triplex or singleplex real-time PCR for the three Mycoplasmas (Table 3).

\section{Analytical specificity of the RespoCheck triplex PCR}

RespoCheck Mycoplasma triplex PCR in silico BLAST searchs (http://blast.ncbi.nlm.nih.gov/Blast.cgi) for the specificity of the $M$. dispar amplicon revealed a $100 \%$ identity (E-value $1 \mathrm{E}^{-46}$ ) for 2 hits for $M$. dispar complete genome sequence. The in silico BLAST search for amplicon of M. bovis we found a $99-100 \%$ identity (E-values

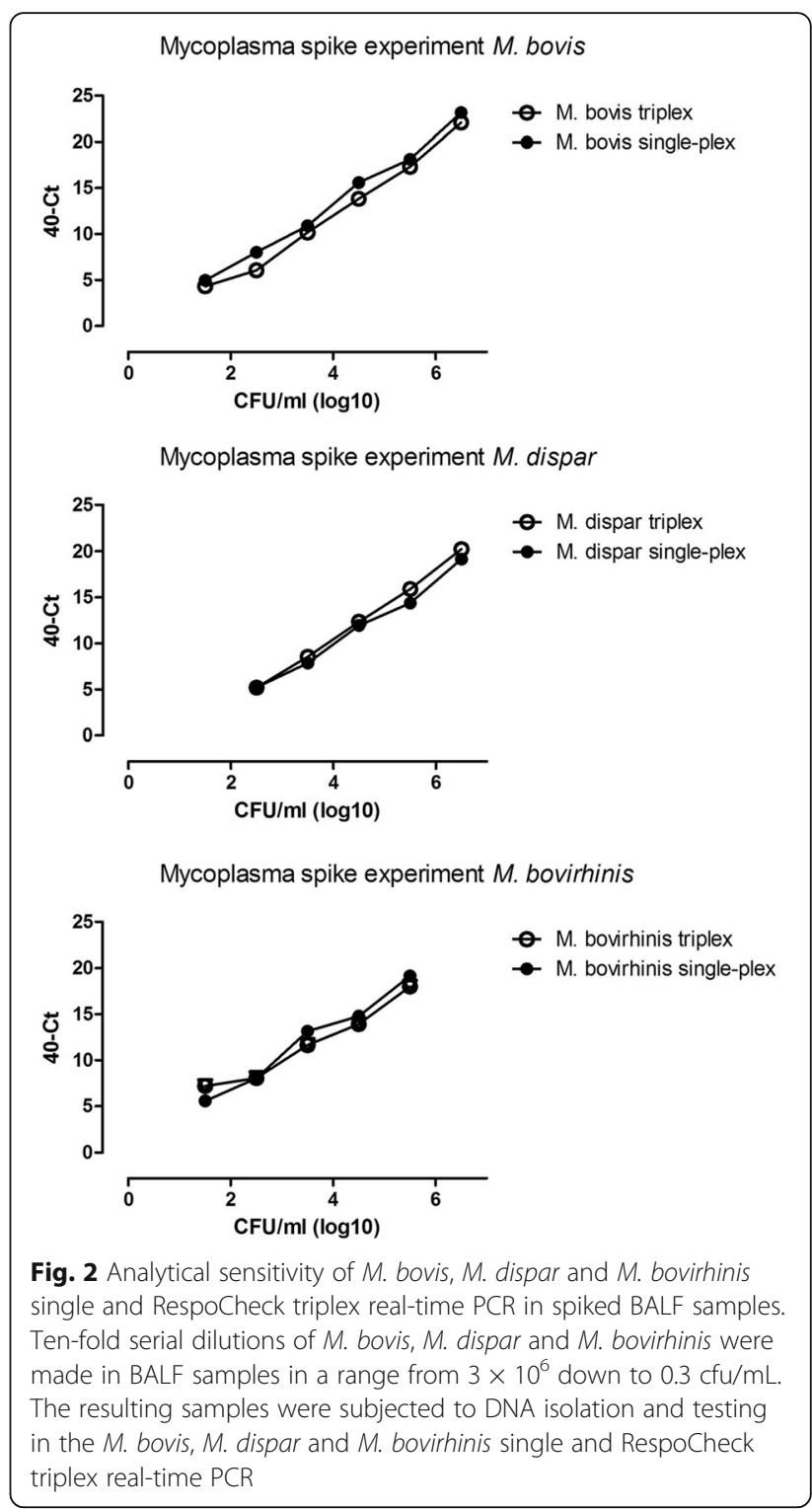

$\left.4 \mathrm{E}^{-43}-6 \mathrm{E}^{-45}\right)$ to 31 complete genome or $16 \mathrm{~S}$ ribosomal partial sequence, and for the amplicon of M. bovirhinis we found a $99-100 \%$ identity (E-values $5 \mathrm{E}^{-50}-1 \mathrm{E}^{-51}$.) For the M. bovirhinis amplicon a $97 \%$ identity (3E-40) was found for 11 hits for Mycoplasma canis (Taxid:29,555).

Seventeen Mycoplasma strains (Table 1) and 107 bacterial strains (Table 2) were used to calculate the analytical specificity of the RespoCheck Mycoplasma triplex PCR. The RespoCheck Mycoplasma triplex real-time assay for detecting $M$. bovis, M. dispar and M. bovirhinis possessed an analytical specificity of $100 \%$ (0 FP), $98.2 \%$ (2 FP) and 99.1\% (1 FP), respectively. No cross-reactivity in the RespoCheck Mycoplasma triplex real-time assay was observed with any of the 107 bacterial strains. The $M$. dispar PCR did however cross-react with Acholeplasma axanthum 
S743 and M. alkalescens PG 31/D 12. In silico sequence data analyses from the $16 \mathrm{~S}$ V3 genomic DNA region showed no similarity of $M$. dispar specific sequences with the $A$. axanthum $\mathrm{S} 743$ and $M$. alkalescens PG 31/D 12 isolates. The M. bovirhinis RespoCheck triplex PCR cross-reacted with $M$. canis with a Ct-value of 20.4. In the $M$. bovis RespoCheck triplex PCR we found a cross-reaction with $M$. agalactiae. Based on the almost $100 \%$ similarity of M. canis PG14 16S rRNA gene and the M. bovirhinis16S rRNA, it is not possible to prevent for this crossreaction.

\section{Diagnostic sensitivity and specificity of the RespoCheck triplex compared with DGGE}

To study the influence of centrifugation of the BALF samples on the PCR results we compared the PCR results from the BALF samples before and after centrifugation $(10 \mathrm{~min}$ at $4600 \times \mathrm{g})$. A significant lower Ct-value $(P<0.05$; non-parametric Wilcoxon statistics) in the RespoCheck Mycoplasma triplex realtime PCR was found for M. bovis and M. dispar in the pellet of the centrifuged BALF samples. Several $M$. bovis, $M$. bovirhinis and $M$. dispar mix-infections could be detected in one BALF sample with a difference of $10 \mathrm{Ct}$-values between the three species and were in accordance with the PCR/DGGE analysis (Fig 3). Therefore we used the pellet of the centrifuged BALF samples (50x concentrated) to determine the presence of the three Mycoplasma species in 44 BALF samples by real-time PCR.

The calculated diagnostic sensitivity and specificity the RespoCheck triplex PCR is reported in Table 4. As the diagnostic specificity is very low (0.1944, $0.739,0.3889$ for $M$. dispar, M. bovis and M. bovirhinis respectively) we analysed the sequence of the produced amplicon of five DGGE negative /PCR positive and five DGGE positive PCR positive samples. The sequence of both products was confirmed as $M$. bovis, $M$. dispar or $M$. bovirhinis, as all sequences had a high E-value (3e-44) and 100\% Query cover (100\%) against the homologue sequence using the BLAST of the NCBI-NIH. Comparison of the Ctvalues of PCR positive/ DGGE negative and the PCR positive/ DGGE positive samples with a nonparametric Mann Whitney test, showed that the Ct values of $M$. dispar and $M$. bovis were significantly lower, $p=0.0026$ and 0.0282 , respectively. In the $M$. bovis and $M$. dispar PCR, the difference in $\mathrm{Ct}$ value between PCR positive/ DGGE positive and PCR positive/ DGGE negative samples is at least 3.2, which indicates a factor of 10 difference in concentration of $M$. bovis and $M$. dispar DNA between these two groups (Fig. 4). As a consequence the diagnostic

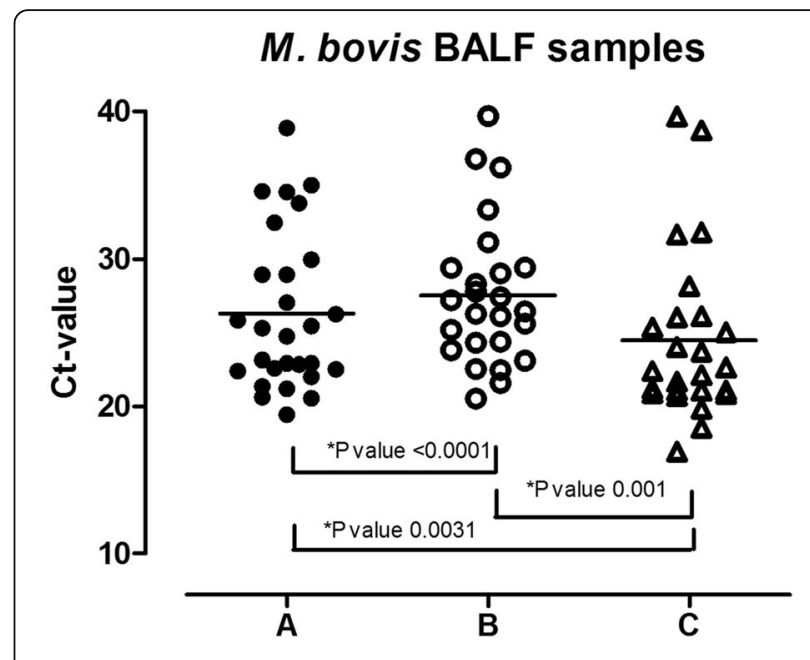

M. dispar BALF samples

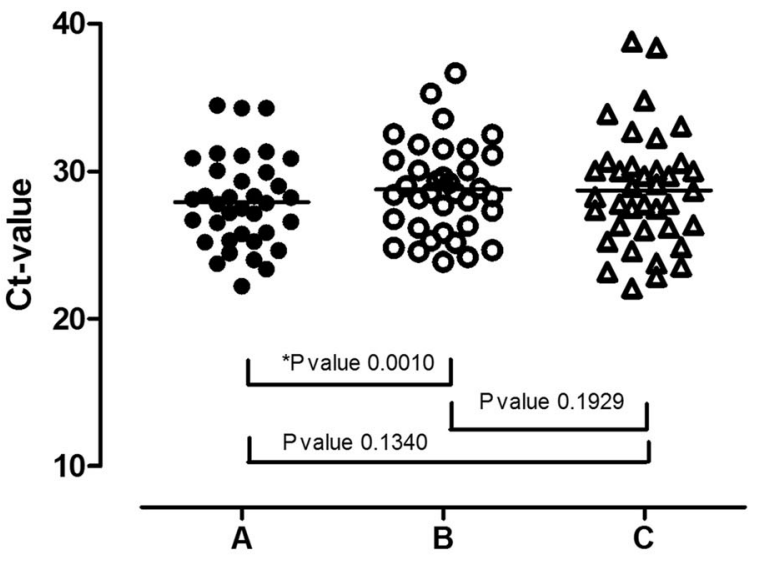

M. bovirhinis BALF samples

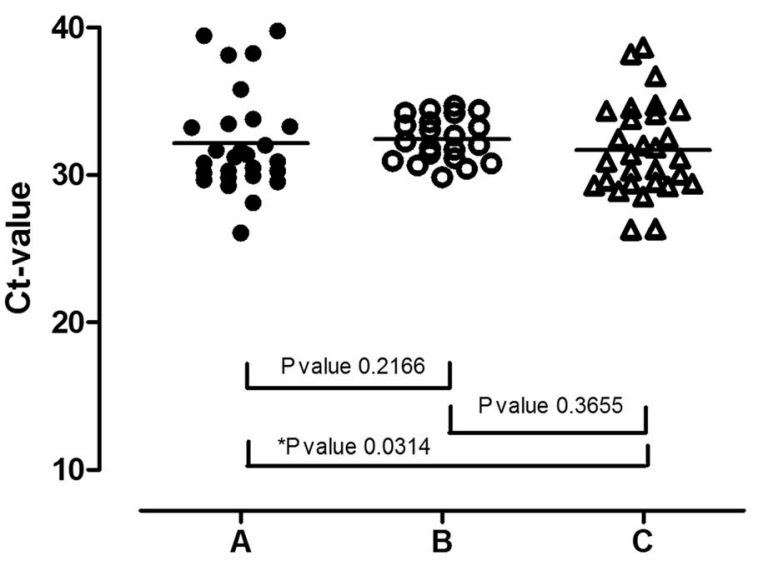

Fig. 3 Ct-values obtained in the RespoCheck Mycoplasama triplex real-time PCR on DNA samples derived from BALF samples from $M$. bovis, M. dispar and M. bovirhinis infected calves. PCRs were performed on three variants of BALF samples: without centrifugation (A), supernatant after centrifugation (B) and sediment of after centrifugation (50 times concentrated) (C) 
Table 4 Diagnostic sensitivity and specificity of the RespoCheck Mycoplasma triplex real-time PCR compared with the PCR/DGGE method

\begin{tabular}{|c|c|c|c|c|}
\hline M. dispar & $\mathrm{PCR}+$ & PCR - & Total & Diagnostic specificity and sensitivity \\
\hline DGGE + & 8 & 0 & 8 & Sensitivity $=1$ \\
\hline DGGE - & 29 & 7 & 36 & Specificity $=0.1944$ (95\% Cl: 0.0819-0.3602) \\
\hline Total & 37 & 7 & 44 & \\
\hline M. bovis & $\mathrm{PCR}+$ & $P C R-$ & Total & Diagnostic specificity and sensitivity \\
\hline DGGE + & 20 & 1 & 21 & Sensitivity $=0.9524$ (95\% Cl: 0.7618-0.9988) \\
\hline DGGE - & 6 & 17 & 23 & Specificity $=0.7391$ (95\% Cl: 0.5159-0.8977) \\
\hline Total & 26 & 18 & 44 & \\
\hline M. bovirhinis & $P C R+$ & $P C R-$ & Total & Diagnostic specificity and sensitivity \\
\hline DGGE + & 7 & 1 & 8 & Sensitivity $=0.8750$ (95\% Cl: 0.4735-0.9968) \\
\hline DGGE - & 22 & 14 & 36 & Specificity $=0.3889$ (95\% Cl: 0.2314-0.5654) \\
\hline Total & 29 & 15 & 44 & \\
\hline
\end{tabular}

specificity of the RespoCheck triplex PCR is undervalued by this method. We compared the results of the M. bovis, M. dispar and M. bovirhinis RespoCheck triplex PCR with the results of the PCR/DGGE analysis. The detection limit of the $M$. bovis, $M$. dispar and $M$. bovirhinis PCR/DGGE analysis was, as determined by APHA, $0.7 \times 10^{3} \mathrm{cfu} / \mathrm{mL}, 16 \times 10^{3} \mathrm{cfu} / \mathrm{mL}$ and $0.5 \times 10^{3} \mathrm{cfu} / \mathrm{mL}$, respectively (Fig. 5).

\section{Discussion}

PCR assays for the detection of Mycoplasmas generally target sequences on the $16 \mathrm{~S}$ rRNA gene [29, 30]. In this study we used the highly conserved $16 \mathrm{~S}$ rRNA

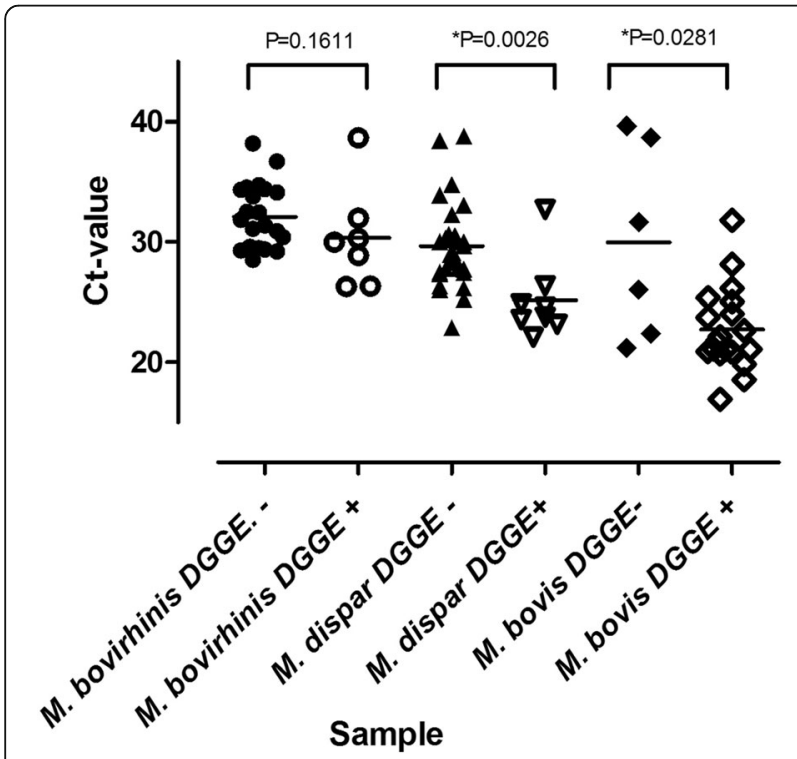

Fig. 4 The Ct-level of DNA derived from BALF samples from M. bovis, $M$. dispar and $M$. bovirhinis infected calves of PCR/DGGE analyses of DGGE APHA negative and positive samples. Significant $P$ values are indicated by * sequence to set up the RespoCheck Mycoplasma triplex real-time PCR assay for the specific detection of $M$. bovis, M. dispar and M. bovirhinis in BALF samples of calves.

The lowest concentration of $M$. dispar which could be detected with the RespoCheck triplex PCR assay is around $300 \mathrm{cfu} / \mathrm{mL}$. With a copy number of $16 \mathrm{~S}$ rRNA of one or two (https://rrndb.umms.med.umich.edu/) and with a test volume of $5 \mu \mathrm{l}$ the lowest concentration which could be detected is around 1-2 cfu/assay. The lowest concentration of $M$. bovis and M. bovirhinis which could be detected with the RespoCheck triplex for M. bovis, and M. bovirhinis is around $0.5 \mathrm{cfu} /$ assay. From the calculated analytical sensitivity of the $M$. bovis, $M$ dispar and $M$. bovirhinis RespoCheck triplex PCR (0.5-2 cfu/assay) we conclude that the RespoCheck triplex PCR has a good analytical sensitivity. It was shown that the use of a pellet from $25 \mathrm{~mL}$ BALF after centrifugation instead of not-centrifuged BALF samples increased the analytical sensitivity of the RespoCheck triplex PCR assay. In order to determine the analytical specificity of the RespoCheck triplex PCR we analysed the DNAs from panels of Mycoplasma and bacterial strains. In the M. bovis RespoCheck Mycoplasma triplex real-time PCR we found a cross-reaction with $M$. agalactiae. Phylogenetic analyses on 16S rRNA sequences and comparing the $16 \mathrm{~S}$ rRNA sequences of $M$. bovis and M. agalactiae [25] at NCBI (www.ncbi.nlm.nih.gov), we found a close relationship between $M$. agalactiae and $M$. bovis, with a $99 \%$ nucleotide identity between their $16 \mathrm{~S}$ rRNA sequences. However, $M$. bovis causes calf pneumonia, mastitis, and arthritis in cattle [16, 31], M. agalactiae is the causal agent of contagious agalactia in goats and sheep [32]. Although unusual, M. agalactiae has been detected from cattle samples [33, 34]. Therefore the cross reactivity for $M$. agalactiae might be a problem for the intended BALF samples in the M. bovis 


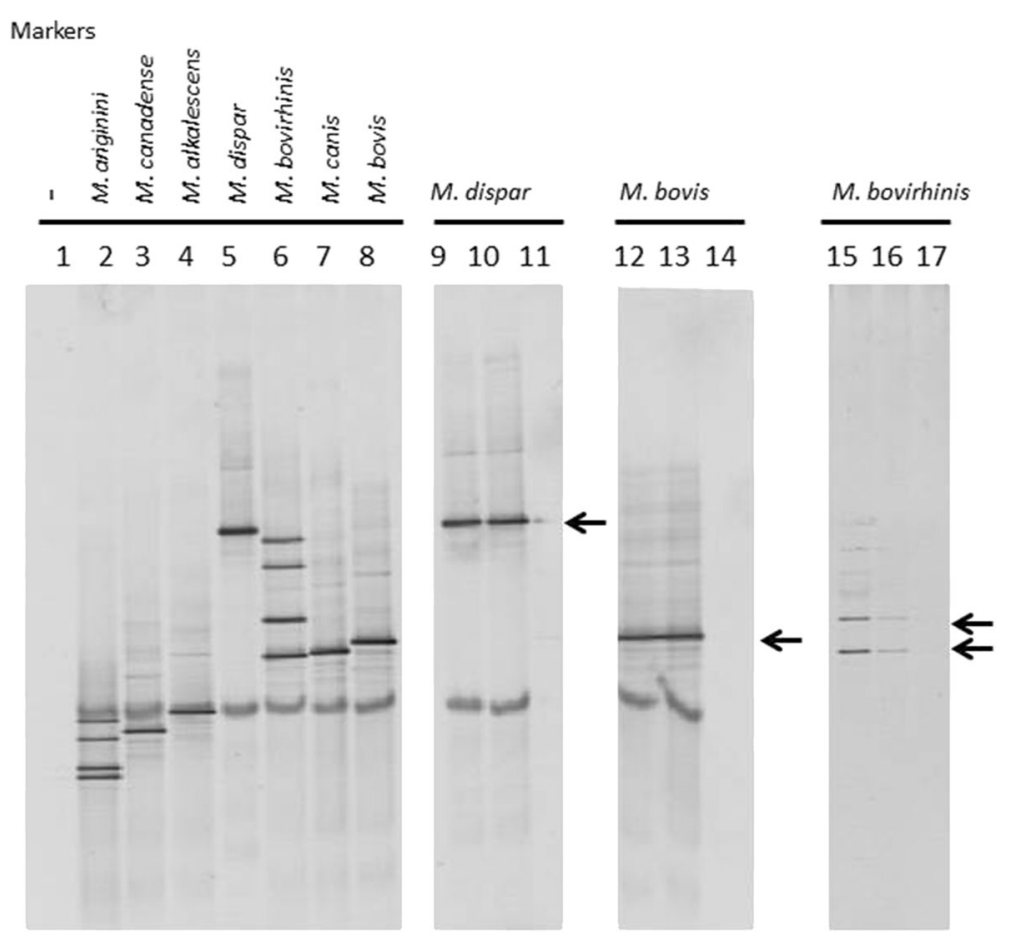

Fig. 5 DGGE fingerprinting profiles of 165 ribosomal DNA fragments obtained after amplification by PCR. Lane 1 contains the negative water control, lanes 2 to 8 contain several Mycoplasma strains as reference (lane and strain designations indicated), lanes 9, 10 and 11 contain three 10-fold serial dilutions of $M$. dispar (starting with $16 \times 10^{4} \mathrm{cfu} / \mathrm{mL}$ ), lanes 12,13 and 14 contain three 10 -fold serial dilutions of $M$. bovis (starting with $7 \times 10^{3} \mathrm{cfu} / \mathrm{mL}$ ) and lanes 15,16 and 17 contain three 10-fold serial dilution of $M$. bovirhinis (starting with $0.5 \times 10^{4} \mathrm{cfu} / \mathrm{mL}$ )

PCR. In the M. bovirhinis RespoCheck triplex real-time PCR one false positive reaction was obtained on DNA from M. canis. M. canis can be isolated from the reproductive tract of dogs, but has not been proved to cause disease in dogs. However, it has been shown to cause clinical signs of pneumonia in experimentally challenged calves [35] and M. canis has been isolated from ruminants in Britain [36, 37]. Depending on the incidence of $M$. canis in ruminants, this may give false-positive results in the M. bovirhinis RespoCheck triplex real-time PCR. DNA samples from $M$. alkalescens and $A$. axanthun showed high Ct-values ( $>35$ ) for $M$. dispar in the RespoCheck triplex real-time PCR, and were therefore classified as false-positive ( $\mathrm{Ct}$ of 40 cycles or less were considered to be positive). M. alkalescens and $M$. bovigenitalium are important Mycoplasmas that can infect cattle and cause mastitis, arthritis and respiratory disease [17]. However, in the sequence analyses of the PCR-positive and DGGE-negative $M$. dispar BALF samples, we did not find any indication for the presence of $M$. alkascens, underlining the high specificity for M. dispar in the RespoCheck triplex real-time PCR.

Monitoring for Mycoplasma species in BALF samples through collection and testing of BALF samples by culture is hampered by the fastidious nutritional requirements, lengthy culture of mycoplasmas, and their susceptibility to growth inhibitors. As a consequence, Mycoplasma culture is time-consuming, costly, and requires specific expertise. Moreover, Mycoplasma species may easily be overgrown by bacterial contaminants or by more rapidly growing Mollicutes, notably Acholeplasmas. The PCR/DGGE method of the APHA can differentiate 13 bovine Mycoplasma species [18] including the target Mycoplasmas of the RespoCheck Mycoplasma triplex real-time PCR and in contrary to the RespoCheck can differentiate between $M$. bovis and M. canis. Additional the PCR/DGGE is capable of detecting mixed cultures, which would have been difficult to detect by culture methods [18]. Therefore we used this method as a reference for determining the diagnostic sensitivity and specificity of the RespoCheck Mycoplasma triplex real-time PCR.

Possibly due to the lower sensitivity of the DGGE analysis compared to the RespoCheck triplex PCR (almost factor 10) and its use as reference method to validate the RespoCheck triplex PCR, the latter test method scores 29, 6 and 22 M. dispar, M. bovis and M. bovirhinis respectively out of 44 more samples as false-positive and therefore the diagnostic specificity of the RespoCheck triplex PCR is underestimated. The transport and storage conditions or differences in DNA preparation of particularly the more diluted BALF samples for the PCR/ DGGE method could have induced a lower sensitivity of 
the PCR/DGGE analysis. The Ct values of the M. bovis, and $M$. dispar PCR positive and DGGE positive samples are significant $(P<0.05$ Mann Whitney test) lower than the $M$. bovis, and $M$. dispar PCR positive DGGE negative samples, which confirms the difference in the analytical sensitivity between the RespoCheck triplex PCR and DGGE analyse. In the $M$. bovis and $M$. dispar PCR, we found a 10 fold difference in the $\mathrm{Ct}$ values between the DGGE positive/ PCR positive and DGGE negative/ PCR positive samples, which indicates a higher diagnostic sensitivity of $M$. bovis and $M$. dispar PCR than the DGGE analyses. Results by DGGE from BALF samples with mixed infections could be reproduced by the triplex PCR, suggesting that there is no significant PCR bias when the triplex PCR is used for Mycoplasma detection in field samples. The PCR has thus a higher analytical sensitivity than the DGGE.

\section{Conclusion}

In conclusion, the RespoCheck Mycoplasma triplex PCRtest appears to be a sensitive and specific test for the detection of M. bovis, M. dispar and M. bovirhinis in BALF samples of calves.

\section{Abbreviations}

BALF: Bronchoalveolar lavage fluid; BRDC: Bovine respiratory disease complex; PCR/DGGE: PCR with denaturing gradient gel electrophoresis fingerprinting

\section{Acknowledgments}

The authors thank Prof. Konrad Sachse (Friedrich-Loeffler-Institut, Federal Research Institute for Animal Health, Jena, Germany) for providing us with DNA from 14 Mycoplasma isolates. The authors thank also The Mycoplasma Team (APHA Woodham Lane Addlestone, Surrey, UK) for performing the PCR/DGGE analysis.

This research was part of the project "Development and application of diagnostics" within the public-private partnership "One Health for Food" in The Netherlands.

\section{Funding}

The research was funded by the Dutch Ministry of Economic Affairs, Productschap Vee en Vlees / Stichting Brancheorganisatie Kalversector (SBK) and supported by the Van Drie Group, MSD Animal Health and Denkavit.

\section{Availability of data and material}

The datasets used and/or analysed during the current study are available from the corresponding author on reasonable request.

\section{Authors' contributions}

$J C$ authored the manuscript, designed the study, performed the $\mathrm{GPCR}$ and analysed the data. $A B$ and FB build an Insignia-based database from which pathogen-specific sequence regions were extracted, designed the oligonucleotide primers and probes and assisted in drafting and editing the manuscript. HW and FW assisted in study design, interpretation of data and editing the manuscript. MK was involved in the microbiological analyses of the samples and participated in the drafting of the manuscript. AA designed and coordinated the field study for the collection of BALF samples and also helped to draft this manuscript. BS conducted and coordinated the field sample collection, performed microbiological analysis of samples and managing the database with results. BK participated in the design of the study and helped in the interpretation of the triplex PCR data. All authors read and critically revised and approved the final manuscript.

\section{Competing interests}

The authors declare that they have no competing interests.

\section{Consent for publication}

Not applicable.

\section{Ethics approval and consent to participate}

Sampling of the calves was granted an exemption from requiring ethics approval by the institutional Animal Experiment Commission "Dier Experimenten Commissie (DEC) Lelystad (2013111.b)" because sampling was performed for diagnostic purposes. Ethics approval is not applicable. Animal handling, including BALF sample collection, was performed or supervised by approved veterinarians Consent was obtained from the farmers for the samples collected at their farm.

\section{Publisher's Note}

Springer Nature remains neutral with regard to jurisdictional claims in published maps and institutional affiliations.

Received: 29 September 2016 Accepted: 3 April 2017

Published online: 08 April 2017

\section{References}

1. Poulsen KP, McGuirk SM. Respiratory disease of the bovine neonate. Vet Clin North Am Food Anim Pract. 2009;25:121-37. doi:10.1016/j.cvfa.2008.10.007.

2. Griffin D, Chengappa MM, Kuszak J, McVey DS. Bacterial pathogens of the bovine respiratory disease complex. Vet Clin North Am Food Anim Pract. 2010;26:381-94. doi:10.1016/j.cvfa.2010.04.004.

3. Srikumaran $\mathrm{S}$, Kelling $\mathrm{CL}$, Ambagala A. Immune evasion by pathogens of bovine respiratory disease complex. Anim Health Res Rev. 2007;8:215-29. doi:10.1017/s1466252307001326

4. Bell CJ, Blackburn P, Elliott M, Patterson T, Ellison S, Lahuerta-Marin A, Ball $\mathrm{HJ}$. Investigation of polymerase chain reaction assays to improve detection of bacterial involvement in bovine respiratory disease. J Vet Diagn Investig. 2014;26:631-4. doi:10.1177/1040638714540166.

5. Woolums AR, Ames TR, Baker JC. The bronchopneumonias (respiratory disease complex of cattle, sheep and goats). In: Smith BP, editor. Large Animal Internal Medicine. 4th ed. St Louis: Mosby, Elsevier; 2009. p. 602-43.

6. Nicholas RA, Ayling RD. Mycoplasma bovis: disease, diagnosis, and control. Res Vet Sci. 2003;74:105-12.

7. Nicholas RA. Bovine mycoplasmosis: silent and deadly. Vet Rec. 2011;168: 459-62. doi:10.1136/vr.d2468.

8. Houghton SB, Gourlay RN. Synergism between Mycoplasma bovis and Pasteurella haemolytica in calf pneumonia. Vet Rec. 1983;113:41-2. doi:10.1136/vr.d2468.

9. Caswell JL, Archambault M. Mycoplasma bovis pneumonia in cattle. Anim Health Res Rev. 2007;8:161-86. doi:10.1017/s1466252307001351.

10. Panciera RJ, Confer AW. Pathogenesis and pathology of bovine pneumonia. Vet Clin North Am Food Anim Pract. 2010;26:191-214. doi:10.1016/j.cvfa. 2010.04.001.

11. Angen O, Thomsen J, Larsen LE, Larsen J, Kokotovic B, Heegaard PM, Enemark JM. Respiratory disease in calves: microbiological investigations on trans-tracheally aspirated bronchoalveolar fluid and acute phase protein response. Vet Microbiol. 2009;137:165-71. doi:10.1016/j.vetmic.2008.12.024.

12. Hirose K, Kobayashi H, Ito N, Kawasaki Y, Zako M, Kotani K, Ogawa H, Sato H. Isolation of Mycoplasmas from nasal swabs of calves affected with respiratory diseases and antimicrobial susceptibility of their isolates. J Vet Med B Infect Dis Vet Public Health. 2003;50:347-51.

13. Gabinaitiene A, Siugzdaite J, Zilinskas H. Laboratory diagnosis of Mycoplasma infection in young cattle. Pol J Vet Sci. 2011;14:87-93.

14. Marques $L M$, Buzinhani $M$, Yamaguti M, Oliveira RC, Ferreira JB, Mettifogo $E$, Timenetsky J. Use of a polymerase chain reaction for detection of Mycoplasma dispar in the nasal mucus of calves. J Vet Diagn Investig. 2007; 19:103-6.

15. Miles K, McAuliffe L, Ayling RD, Nicholas RA. Rapid detection of Mycoplasma dispar and M. Bovirhinis using allele specific polymerase chain reaction protocols. FEMS Microbiol Lett. 2004;241:103-7. doi:10.1016/j.femsle.2004.10.010.

16. Sachse K, Salam HS, Diller R, Schubert E, Hoffmann B, Hotzel H. Use of a novel real-time PCR technique to monitor and quantitate Mycoplasma bovis infection in cattle herds with mastitis and respiratory disease. Vet J. 2010;186:299-303. doi:10.1016/j.tvjl.2009.10.008. 
17. Kobayashi H, Hirose K, Worarach A, Paugtes P, Ito N, Morozumi T, Yamamoto K. In vitro amplification of the 16S rRNA genes from Mycoplasma bovirhinis, Mycoplasma alkalescens and Mycoplasma bovigenitalium by PCR. J Vet Med Sci. 1998:60:1299-303.

18. McAuliffe L, Ellis RJ, Lawes JR, Ayling RD. Nicholas RA 165 rDNA PCR and denaturing gradient gel electrophoresis; a single generic test for detecting and differentiating Mycoplasma species. J Med Microbiol. 2005;54:731-9. doi:10.1099/jmm.0.46058-0.

19. Schnee C, Schulsse S, Hotzel H, Ayling RD, Nicholas RA, Schubert E, Heller M, Ehricht R, Sachse K. A novel rapid DNA microarray assay enables identification of 37 Mycoplasma species and highlights multiple Mycoplasma infections. PLoS One. 2012;7:e33237. doi:10.1371/journal.pone.0033237.

20. Aluotto BB, Wittier RG, Williams CO, Faber JE. Standardized bacteriologic techniques for the characterization of mycoplasma species. Int J Syst Bacteriol. 1970;20:35-58.

21. Fogarty U, Quinn PJ, Hannan J. Bronchopulmonary lavage in the calf: a new technique. Ir Vet J. 1983;37(2):35-8.

22. Phillippy AM, Mason JA, Ayanbule K, Sommer DD, Taviani E, Huq A, Colwell RR, Knight IT, Salzberg SL. Comprehensive DNA signature discovery and validation. PLoS Comput Biol. 2007;3:e98. doi:10.1371/journal.pcbi.0030098.

23. Peer $Y$ van de, Chapelle $S$, de Wachter $S$. A quantitative map of nucleotide substitution rates in bacterial RNA. NAR 1996; 24:3381-3391.

24. Saah A, Hoover DR. "Sensitivity" and "specificity" reconsidered: the meaning of these terms in analytical and diagnostic settings. Ann Intern Med. 1997;126:91-4.

25. Pettersson B, Uhlén M, Johansson KE. Phylogeny of some mycoplasmas from ruminants based on $16 \mathrm{~S}$ rRNA sequences and definition of a new cluster within the hominis group. Int J Syst Bacteriol. 1996;46:1093-8. doi:10. 1099/00207713-46-4-1093.

26. Altschul SF, Gish W, Miller W, Myers EW, Lipman DJ. Basic local alignment search tool. Mol Biol. 1990;215:403-10. doi:10.1016/s0022-2836(05)80360-2.

27. Martin SW. Estimating disease prevalence and the interpretation of screening test results. Prev Vet Med. 1984;2:463-72.

28. Mackinnon A. A spreadsheet for the calculation of comprehensive statistics for the assessment of diagnostic tests and inter-rater agreement. Comput Biol Med. 2000:30:127-34.

29. Chávez González YR, Ros Bascuñana C, Bölske G, Mattsson JG, Fernández Molina C, Johansson KE. In vitro amplification of the 16S rRNA genes from Mycoplasma bovis and Mycoplasma agalactiae by PCR. Vet Microbiol. 1995; 47:183-90.

30. van Kuppeveld FJ, van der Logt JT, Angulo AF, van Zoest MJ, Quint WG, Niesters HG, Galama JM, Melchers WJ. Genus and species-specific identification of mycoplasmas by 165 rRNA amplification. Appl Environ Microbiol. 1993;59:655.

31. Pfützner H, Sachse K. Mycoplasma bovis as an agent of mastitis, pneumonia, arthritis and genital disorders in cattle. Rev Sci Tech. 1996;15:1477-94.

32. Lambert M. Contagious agalactia of sheep and goats. Rev Sci Technol Off Int Epizoot. 1987;6:6677-711.

33. Catania S, Gobbo F, Schiavon E, Nicholas RAJ. Severe otitis and pneumonia in adult cattle with mixed infection of Mycoplasma bovis and Mycoplasma agalactiae. Vet Rec Case Rep. 2016;4:e000366. doi:10.1136/vetreccr-2016000366

34. Bashiruddin JB, Frey J, Königsson MH, Johansson KE, Hotzel H, Diller R, de Santis P, Botelho A, Ayling RD, Nicholas RA, Thiaucourt F, Sachse K. Evaluation of PCR systems for the identification and differentiation of Mycoplasma agalactiae and Mycoplasma bovis: a collaborative trial. Vet J. 2005;169:268-75.

35. Nicholas R, Baker S, Ayling R, Stipkovits L. Mycoplasma infections in growing cattle. Cattle Practice. 2000;8:115-8.

36. Megid R, Nicholas RA, Miles RJ. Biochemical characterization of Mycoplasma bovirhinis, Mycoplasma dispar and recent bovine isolates of Mycoplasma canis. Vet Res Commun. 2001;25:1-12.

37. Ayling RD, Bashiruddin SE, Nicholas RA. Mycoplasma species and related organisms isolated from ruminants in Britain between 1990 and 2000. Vet Rec. 2004;155:413-6.

\section{Submit your next manuscript to BioMed Central and we will help you at every step:}

- We accept pre-submission inquiries

- Our selector tool helps you to find the most relevant journal

- We provide round the clock customer support

- Convenient online submission

- Thorough peer review

- Inclusion in PubMed and all major indexing services

- Maximum visibility for your research

Submit your manuscript at www.biomedcentral.com/submit
Biomed Central 